\title{
Optoelectronic lessons as an interdisciplinary lecture
}

Dan Wu, Maocheng Wu, Jihua Gu

Dan Wu, Maocheng Wu, Jihua Gu, "Optoelectronic lessons as an interdisciplinary lecture," Proc. SPIE 10452, 14th Conference on Education and Training in Optics and Photonics: ETOP 2017, 104521M (16 August 2017); doi: 10.1117/12.2269165

SDIE Event: 14th Conference on Education and Training in Optics and Photonics, ETOP 2017, 2017, Hangzhou, China 


\title{
Optoelectronic lessons as an interdisciplinary lecture
}

\author{
Dan $\mathrm{Wu}^{\mathrm{a}}$, Maocheng $\mathrm{Wu}^{\mathrm{b}}$, Jihua $\mathrm{Gu}^{* \mathrm{~b}}$ \\ ${ }^{\mathrm{a}}$ Wenzheng College, Soochow University, Suzhou 215104, China; ${ }^{\mathrm{b}}$ College of Physics, \\ Optoelectronics and Energy, Soochow University, Suzhou 215006, China
}

\begin{abstract}
It is noticed that more and more students in college are passionately curious about the optoelectronic technology, since optoelectronic technology has advanced extremely quickly during the last five years and its applications could be found in a lot of domains. The students who are interested in this area may have different educational backgrounds and their majors cover science, engineering, literature and social science, etc. Our course "History of the Optoelectronic Technology" is set up as an interdisciplinary lecture of the "liberal education" at our university, and is available for all students with different academic backgrounds from any departments of our university. The main purpose of the course is to show the interesting and colorful historical aspects of the development of this technology, so that the students from different departments could absorb the academic nourishment they wanted. There are little complex derivations of physical formulas through the whole lecture, but there are still some difficulties about the lecture which is discussed in this paper.
\end{abstract}

Keywords: optoelectronic lessons, liberal education, interdisciplinary lecture

\section{INTRODUCTION}

During the past five years, more and more students in college are passionately curious about the optoelectronic technology, since optoelectronic technology has advanced extremely quickly and its applications could be found in a lot of domains. It is an interesting phenomenon that these students are not only from the departments of science and engineering, but also from that of literature, economy and arts. Students who are interested in optoelectronic technology can be divided into two branches, namely science and engineering, and liberal arts. As a matter of fact that these two kinds of students have few communications with each other after class and have little concepts about both sides of the major. This is not ideal for the university education. In the 1950's, the historian Joseph Needham ${ }^{[1]}$ asked the famous Grand Questions "Why China had been overtaken by the West in science and technology, despite its earlier successes", "Why did modern science, the mathematization of hypotheses about Nature, with all its implications for advanced technology, take its meteoric rise only in the West at the time of Galileo [but] had not developed in Chinese civilization or Indian civilization?", which have inspired thousands of trying answers in the last decades. One of them is that China hasn't have modern universities for too long time. China has a lot of universities now, but has a long way to go for the modernization, despite she has achieved great success during the last decades. One problem is how to make students gentleman (Junzi in chinese) and scholars. Our course "History of the Optoelectronic Technology" is set up as an interdisciplinary lecture of the "liberal education" at our university, and is available for all students with different academic backgrounds from any departments of our university. The main purpose of the course is to show the interesting and colorful historical aspects of the development of this technology, so that the students from different departments could absorb the academic nourishment they wanted. Through the course, the view of the students is broaden and the idea of liberal education is partly realized, which is introduced by the Europe, especially by the Humboldt University of Berlin in 1850's and then inherited and developed by the European and American universities ${ }^{[2]}$.

In order to inspire the curiosity of the students, broaden their vision, and spread the scientific ideas, discussions between the students and professors are encouraged. The internet educational resources are also used as an extracurricular video. There are little complex derivations of physical formulas through the whole lectures, however there are still some difficulties about the lecture, which is also presented in this paper.

*Correspondent author: jhgu@suda.edu.cn

14th Conference on Education and Training in Optics and Photonics: ETOP 2017, edited by Xu Liu,

Xi-Cheng Zhang, Proc. of SPIE Vol. 10452, 104521M - @ 2017 ICO, IEEE, OSA, SPIE

CCC code: $0277-786 X / 17 / \$ 18 \cdot$ doi: $10.1117 / 12.2269165$

Proc. of SPIE Vol. $10452104521 \mathrm{M}-1$ 


\section{PHILOSOPHIC AND CULTURAL ASPECTS}

Generally speaking, the Chinese philosophy is evidently different from that of western, which plays an important role in the modern science, though ancient China like ancient Greek had the most glorious academic period in the history in the "Schools" (see Fig.1 ).

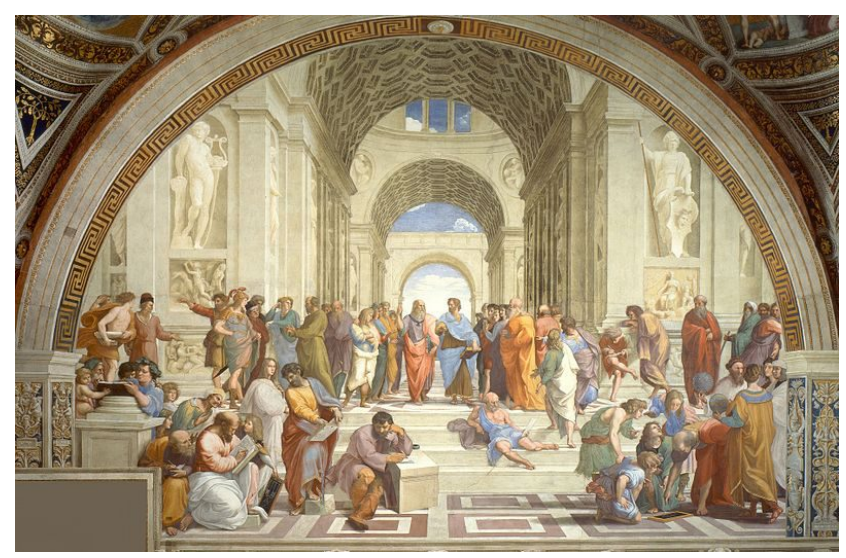

The school of Athens (ca. BC 400, painting)

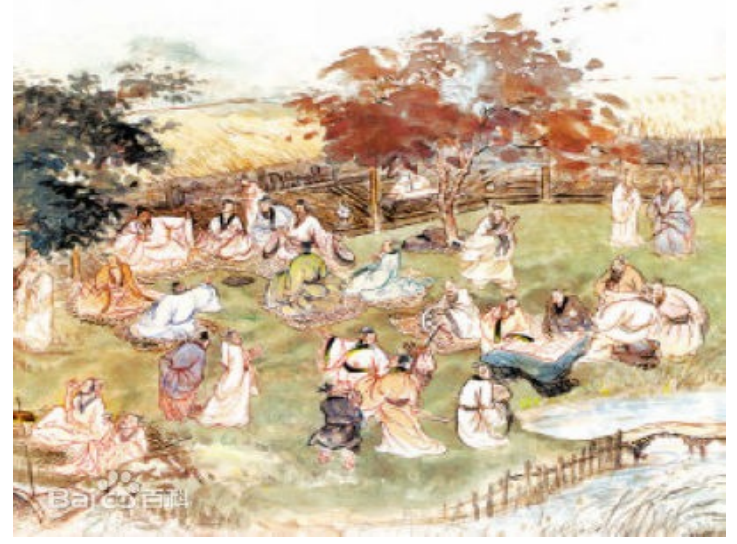

The school of Jixia (ca. BC 350. painting)

Fig. 1 The ancient schools in Greek and in China.

In the branch of Chinese thoughts Taoism, Yin-Yang ("dark-bright", Fig. 2) describe how seemingly opposite or contrary forces may actually be complementary, interconnected, and interdependent in the natural world, and how they may give rise to each other as they interrelate to one another ${ }^{[3]}$. People should be harmony with the nature. However, this was not the dominant idea in the next 2000 years since created, while people focused on the relations between each other and aimed to become officials, very few persons are encouraged or interested in taking part in activities of science and technology.

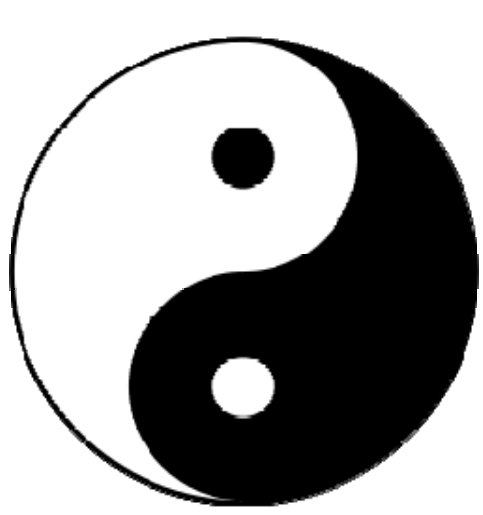

Fig. 2 The "Yin-Yang symbol" (Taijitu).

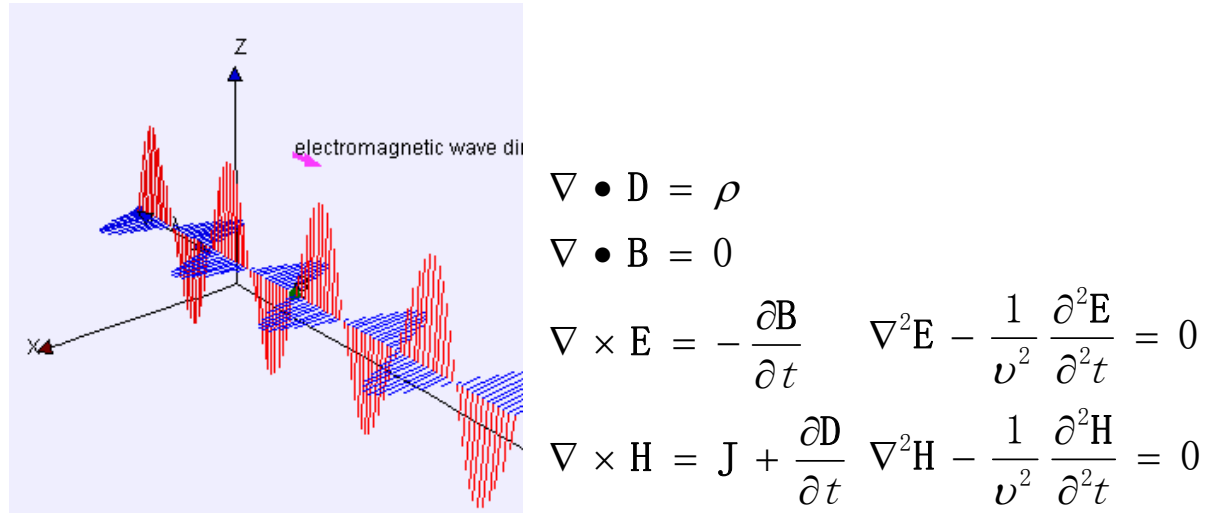

Fig. 3 Maxwell Eqs. and wave Eqs.

"The 10years disaster" (The Cultural Revolution, 1966-1966) destroyed the campus culture thoroughly, which was constructed over 100 years, and the reconstruction of it needs a procedure like the Renaissance, that began in Europe in 14th century and popularized science and spread the idea of freedom.

Let's give a short glance to the ancient history. The Greeks laid the foundation of natural science because the Greek mind was essentially an inductive and deductive mind (represented by Aristotle), The Egyptians developed geometry and astronomy which required an analytical mind. In the traditional Chinese thought, intuition, feelings and dialectics are the main thinking methods instead of inductive and deductive reasoning methods, which very important to the science and technology.

In the long Chinese history, mathematics had not been paid attention to by Chinese people, though in modern China a great number of outstanding mathematicians emerging. Most Chinese students have loves to the nature only for poems, but are lack of enthusiasm for "beautiful" formulas. In order to excite their interests in physical and mathematical 
formulas, some interesting equations are introduced in the class. For example, Maxwell Eqs. are like a sealed book for many students due to the complex differential operators. When the electromagnetic laws behind the equations are interpreted, the reasoning of wave equations and the grand prediction of the existence of the electromagnetic wave surprise the students enormously (Fig. 3). A vivid memories about electromagnetic laws are obtained by students.

\section{TOPICS CHOSEN FOR LESSONS}

In the developing history of optoelectronics, there are numerous interesting and important events to present to students. It is well known that human began to study light very long ago. In ancient Arabian world as well as in ancient China, people studied light. For example, the philosopher Mozte (BC 468-376) studied the imaging of pinholes and mirrors. Our focus, however, is put on modern optics mainly and the topics of the lectures are listed as follows ${ }^{[4,5,6,7]}$ :

- Johannes Kepler, (1571-1630), the inverse-square law the intensity of propagating light, reflection, refraction, Snell's law.

- Christiaan Huygens (1629-1695), the interference experiments of Thomas Young, wave theory of light.

- Galileo Galilei (1564-1642), telescope, microscope.

- Isaac Newton (1643-1727), the refraction of light by prism, d refraction of light, spectrum of colors, reflecting telescope.

- Augustin-Jean Fresnel (1788 -1827), diffraction of light, Huygens-Fresnel principle.

- James Clerk Maxwell (1831 - 1879), Maxwell equations, theory of electromagnetic radiation.

- Max Planck (1858 -1947), black body, wave-particle duality of light, quantum mechanics, photons.

- Albert Einstein (1879-1955), the photoelectric effect, the general theory of relativity.

- Laser: the principle of "The stimulated emission of radiation". Applications: optical disk drives, laser printers, barcode scanners, laser surgery.

- Light source: color temperature, incandescent lamp, fluorescent lamp, LED

- Optical fiber: total internal reflection, waveguide, fiber-optic communication, fiber-optic sensors and fiber lasers.

- Semiconductor, diodes, transistors, photoresistor, photovoltaic cell, various photodetectors.

- Electro-optic crystal, modulation of light.

- Camera, CCD, imaging system.

- Quantum entanglement, quantum tunneling, quantum logic gates.

In the course, there are little complicated derivations of formulas. It is found that the backgrounds and some interesting stories behind the theories and experiments attract most students, applications related to the physical laws are illustrated through different examples.

\section{INTERACTIONS WITH THE STUDENTS IN THE CLASS}

In our class, there are a variety of interactions between the professor and the students, as well as a lot of discussions among the students. The internet educational resources are used to inspire the curiosity of the students, broaden their vision, and spread the scientific ideas. For example, "the light fantastic-the history of the electromagnetism", filmed by BBC, which is offered by the Netease Opencourse, a popular Chinese Web site, are introduced to the students as an extracurricular video. Most of the classroom discussions are based on these videos. These videos make the scientific history reappear with the proposing of the theories and the simulating of the fascinating experiments. Students are inspired to simulate those famous formulas by computer software, as shown in Fig.4 and Fig.5. 


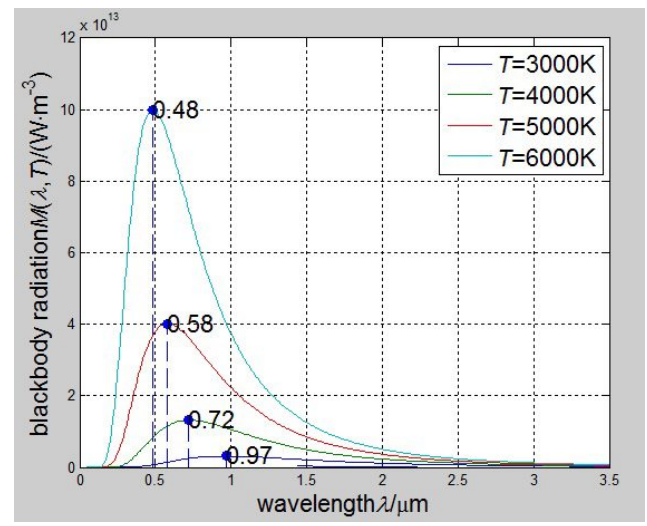

Fig. 4 The numerical simulation of blackbody radiation by a student.

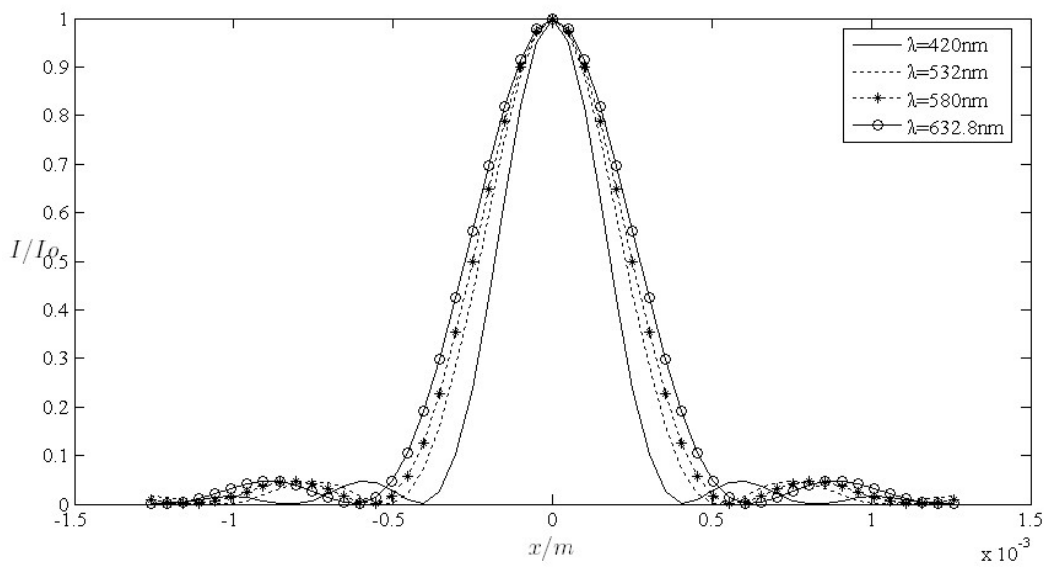

Fig.5 The numerical simulation of Fraunhofer Diffraction by a student.

\section{DISCUSSIONS}

Actually our lectures can be regarded as a kind of "History of Science and Technology" confined in the domain of optoelectronics. The main purpose of the lectures is that we try to give students more details about the physical laws, more historical events behind the physical laws, while the complex derivations of formulas are less important. The different academic backgrounds of the students taking part in the lectures make it really difficult for the teacher to explain these laws. The homework can be divided into different sorts, some of them involve the numerical simulations, which require more programming skills of the students, some of them refer to the applications of the optoelectronic technology, which need our students to do a lot of collection of the recent research on optoelectronic technology.

\section{REFERENCES}

[1] Joseph Needham, "Science and Civilisation in China", Cambridge University Press, 1954

[2] Joseph Agassi, "Science and Culture", Springer Science +Business Media, 2003

[3] Lin Yutang, "My Country and My People", Reynal \& Hitchcock, Inc., 1935

[4] Eugene Hecht, "Optics", Higher Education Press, 2004

[5] Djafar K.Mynbev, "Fiber-Optic Communications Technology", Lowell L.Scheiner , 2002

[6] Amnon Yariv, "Optical Electronics in Modern Communications" (Fifth Edition), 2002

[7] Chritopher C. Davis, "Lasers and Electro-Optics", Cambridge University Press, 1996 